\title{
Manufacture and multi-physical characterization of aluminum/high-density polyethylene functionally graded materials for green energy building envelope applications
}

\author{
F. L. Chen ${ }^{\mathrm{a}}$, X. He ${ }^{\mathrm{a}}$, H.M. Yin ${ }^{\mathrm{a}, *}$ \\ ${ }^{a}$ Department of Civil Engineering and Engineering Mechanics, Columbia University, 610 Seeley W. Mudd 500 West 120 th Street, \\ New York, NY 10027
}

\begin{abstract}
An aluminum/High-Density Polyethylene (HDPE) functionally graded material (FGM) has been fabricated as an essential component of a multifunctional building envelope for high performance of energy efficiency and sustainability. The mass production of the FGM was realized by using coarse Aluminum (Al) particles and fine HDPE powder through a vibration-sedimentation process. The gradation of the FGM across its thickness direction was analyzed by developing a modified Rice method, from which five different uniform Al-HDPE samples were made to characterize the material properties of the five sub-layers of the FGM. The mechanical and thermal physical properties of the FGM such as Young's modulus, Poisson ratio, thermal expansion coefficients and thermal conductivities were obtained by various experimental characterizations. A prototype FGM panel with water tubes embedded was fabricated by the vibration and sedimentation combined approach and the thermal efficiency of the FGM panel was evaluated. Under an irradiation level of $620 \mathrm{w} / \mathrm{m}^{2}$ and a water flowing rate of $60 \mathrm{ml} / \mathrm{min}$, a $22.3^{\circ} \mathrm{C}$ water temperature increase and an average $18.7^{\circ} \mathrm{C}$ surface temperature decrease of the FGM panel were achieved, which demonstrates that significant PV conversation efficiency improvement can be realized for both electricity generation and heat collection by the presented FGM panel. The presented fabrication procedures and the associated experimental characterization methods and results can serve as a baseline for quality control of the manufacture of the green energy building envelope materials.
\end{abstract}

Keywords:

Building integrated photovoltaic thermal (BIPVT); Functional graded material; Particle-size distribution; Sedimentation; Rice method;

\section{Introduction}

Buildings consume as much as $40 \%$ of all energy and a significant percentage of non-renewable natural resources and non-recyclable building materials [1]. In order to make dramatic improvements with regard to conserving energy and natural resources, and improving energy efficiency of buildings, it is necessary to revisit the way building envelopes are designed and manufactured. As the PV technology has advanced in recent years, integrated technologies for harvesting solar energy, such as the Building-Integrated Photovoltaic (BIPV) system, have evolved as a promising solution for meeting energy and environmental challenges $[2,3]$. The building integration schemes are gaining a worldwide recognition due to the considerable savings on building materials, construction, and operation. BIPVs are photovoltaic materials that are used to replace

\footnotetext{
${ }^{*}$ Corresponding author. Tel.: +1 212851 1648; Fax: +1 2128546267

Email addresses: fangliang. chen@columbia.edu (F. L. Chen), xh2205@columbia.edu (X. He), yin@civil.columbia.edu (H.M. Yin)
} 
conventional building materials in parts of the building envelope such as the roof, skylights, or facades [4]. In addition to the power supply function, the advantage of BIPV over most common non-integrated systems is that the initial cost can be offset by reducing the amount spent on building materials and labor normally used to construct the part of the building that the BIPV modules replace. These advantages make BIPV one of the fastest growing segments of the photovoltaic industry $[5,6,7,8,9,10]$.

Recent research work conducted at Columbia University $[11,12]$ have shown great potential to harvest solar energy efficiently by developing a building integrated photovoltaic thermal (BIPVT) roofing panel with Functionally Grated materials (FGMs) as an essential component. The innovative idea of this BIPVT is schematically illustrated in Fig. 1, where a photovoltaic (PV) solar cell (laminated by a protective layer) directly transfer solar energy into electricity; the PV layer bonded to a structural substrate through a FGM layer, in which water tubes are cast to harvest heat energy by water flow and thus control the panel temperature. It's well known that the energy efficiency of most solar cells greatly depends on the operational temperature. In general, in-service surface temperatures of a PV module are commonly $40-50{ }^{\circ} \mathrm{C}$ above ambient, resulting in 16-20\% reductions in electricity generation and power output [13]. In addition, large diurnal thermal cycles and aging effects limit the lifetime of solar panels to about 30 years. In this sense, in order to improve both the performance and design life of a PV module, a cooling technique of the PV panel is highly desirable. The FGM layer shown in Figure 1 is designed to fulfill this function. The purpose of the proposed FGM layer is to create a light-weight layer of solar roofing panel with a varying thermal conductivity in the thickness direction. The FGM layer gradually transits material phases from metal dominated to polymer materials. Water tubes are embedded in the top part of the FGM layer, where the high aluminum concentration creates high thermal conductivity so that heat flow from surface can be immediately transferred to water tubes in all directions, yet be insulated by the bottom part of polymer layer. The proposed PVT panel can be integrated into the building skin with water circulation, flow control, and heat storage and utilization systems. Solar energy is collected by BIPVT panels in form of electricity and heat. Electricity can be used locally or transmitted to the grid, while the heat can be stored or directly used as indoor or external heat supply such as floor heating, clean drying, and swimming pools.

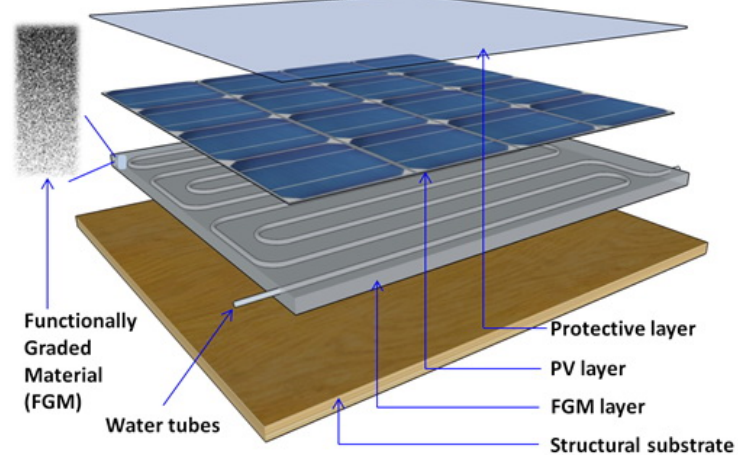

(a)

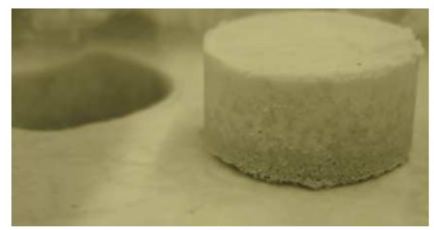

(b)

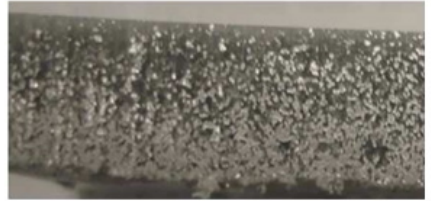

(c)

Figure 1: Schematic illustration of the hybrid solar roofing panel.

FGMs are heterogeneous materials which are composed of two or more phases with different properties, sizes and shapes. In a typical FGM, the volume fractions of the constituents vary gradually, resulting in a composite with continuously graded material properties, such as mechanical, electrical, and thermal parameters, at the macro level. Such a distinctive feature of the FGMs can be exploited to obtain properties that are not offered by conventional materials. Research results obtained so far have demonstrated that FGMs have great potential for improving material and structural performance in many engineering applications precisely because of their spatially graded heterogeneous microstructure $[14,15,16]$. In particular, by grading 
and tailoring the internal microstructure and distribution of the constituents in the FGMs, the designer can integrate both the material and structural aspects into the final design and product, which offers a number of advantages over traditional methods of tailoring traditional composite materials and structural components [17].

In recent years, Yin and his co-workers developed a sedimentation method for FGM manufacturing $[18,19]$, which uses a suspension to create the graded microstructure of the mixture. They have used aluminum (Al) powder and high density polyethylene (HDPE) powder, mixed thoroughly with ethanol, to fabricate FGM layers in the laboratory. The reason to use ethanol instead of water is twofold: (a) because of water's specific gravity is between those of $\mathrm{Al}$ and HDPE, it is often leads to laminated deposition instead of graded microstructure; and (b) when the sedimentation process is long (more than 10 hours), a chemical reaction between $\mathrm{Al}$ and water has been observed, which produces hydrogen and alumina. Because $\mathrm{Al}$ and HDPE have significantly different specific gravities (2.7 and 0.95 , respectively) and due to the particle size distribution (50-150 $\mu \mathrm{m}$ and 5-30 $\mu \mathrm{m}$, respectively), the two types of powders will fall down at different velocities and thus create a graded microstructure. When a desired graded microstructure forms, the ethanol is filtered out for reuse. By heating up the graded powder mix in a vacuum oven, the HDPE powder will be melt so as to form a composite of $\mathrm{Al}$ particles dispersed in the HDPE matrix with graded microstructure. After curing it, solid FGM layer can be obtained. The sedimentation process has been modeled by Stokesian dynamics and dissipative particle dynamics (DPD) [20]; Such a sedimentation method was shown to be effective in fabricating small size samples; however, it consumes large amount of ethanol and thus turns out to be cost inefficient. Later, a small size $(1 \mathrm{ft} \times 1 \mathrm{ft})$ FGM panel was fabricated by simply laying mixed powders with different mixing ratios of HDPE and Al particles into different layers to form a gradated composite panel $[11,12,21]$. Although overall gradation was achieved across its thickness direction, it is difficult for such a simple layering method to control and assure the quality of the final product and it is hard to be scalable for larger sample fabrication.

To improve the fabrication efficiency and quality assurance, a novel vibration and sedimentation combined approach is proposed in this study toward the mass production and its quality control of the FGM. The final production of the FGM layer gradually transits material phases from well-conductive side (aluminum dominated) attached with a photovoltaic (PV) solar cell to another highly insulative side (polymer materials) bonded to a structural substrate. Due to the gradual change of the phase proportion of materials, only a small amount of aluminum powder is needed. This reduces the cost of the panel as the aluminum material is relatively expensive. Since the volume fraction of aluminum (Al) powder continuously varies in the thickness direction, the thermo-mechanical property distribution changes smoothly, which avoids the thermal stress concentration across layers and increases the structural integrity and durability of the panels.

In the following, Section 2 introduces the mass production procedure of the FGM by using coarse aluminum powder and fine HDPE powder through a vibration-sedimentation process. The gradation analysis of the FGM across its thickness direction is further realized by developing a modified Rice method. Section 3 provides the experimental characterizations of the mechanical properties of the FGM. Section 4 presents the thermal physical properties of the FGM. Section 5 shows the thermal performance and demonstrates its overall energy efficiency of an integrated roofing panel used for energy efficient building envelope. Finally, some conclusive remarks are provided in Section 6.

\section{Fabrication of FGM with HDPE and aluminum powder}

\subsection{Material and mix design}

The proposed FGM was made by coarse aluminum powder and high-density polyethylene (HDPE) through a vibration and sedimentation combined approach. The size of the coarse aluminum powder (Al111) ranges from 100 to $600 \mu \mathrm{m}$ with a median size of $300 \mu \mathrm{m}$; while the size of the finer high-density polyethylene (HDPE) powder ranges from 1 to $100 \mu \mathrm{m}$ with a median size of $25 \mu \mathrm{m}$. The particle size 
distribution of both material were measured by particle analyzer (Mastersizer 2000, Malvern). Through scanning electron microscope (SEM) observations, it was found that the shape of the Al particles is irregular with certain elliptical-like (Figure 2 (a)) but the HDPE powders are more spherical (Figure 2 (b)).

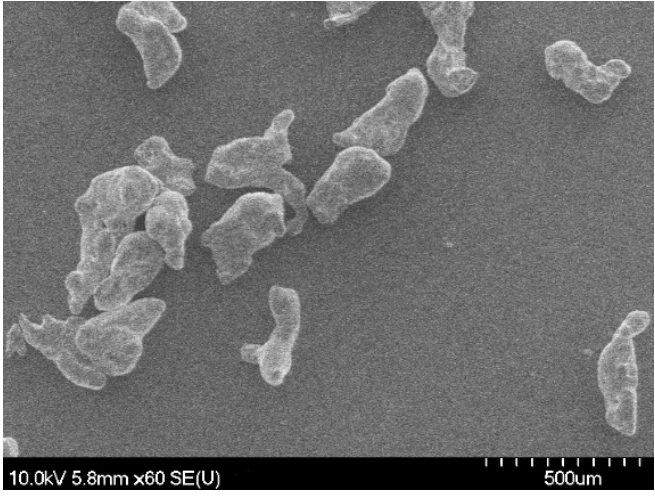

(a)

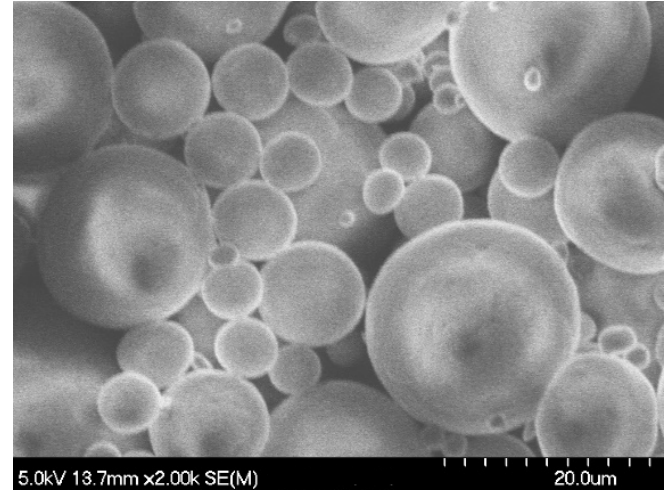

(b)

Figure 2: SEM observation of (a) aluminum (Al-111); and (b) high-density polyethylene powder.

Theoretically, a good gradation of Al-HDPE FGM layer means the volume fraction of Al particles decrease from $100 \%$ to $0 \%$ from the bottom to the top of the settled layer, while the HDPE powders have a completely opposite trend. However, in practice, it was found that the maximum volume fraction of Al to HDPE in a mixed composite can only reach about $60 \%$ due to the fact that enough HDPE materials are required to solidify the $\mathrm{Al}$ particles during the sintering process afterwards. Considering this, the desired gradation of the AL-HDPE FGM in terms of volume fraction of aluminum to the FGM is designed to be from 0 to $50 \%$ across its thickness. Aiming at this gradation, a mixing design of the FGM with an appropriate volume ratio of $\mathrm{Al}$ to $\mathrm{HDPE}$ as 1:3 was determined after a series of tries and comparisons, and the ethanol added for the mixing was chosen by the weight ratio of ethanol to the mixed powder as $28 \%$. The introduced mass of Al, HDPE and Ethanol based on the final mix design for a 12" x 12" x 0.5 " FGM panel is $876.05 \mathrm{~g}$, $895.52 \mathrm{~g}$ and $688.95 \mathrm{~g}$, respectively.

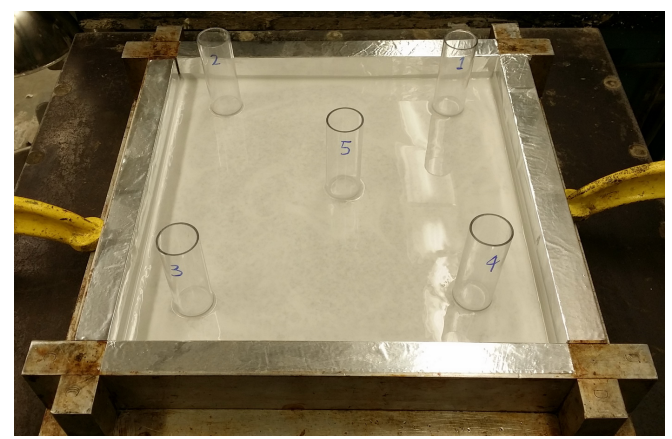

(a)

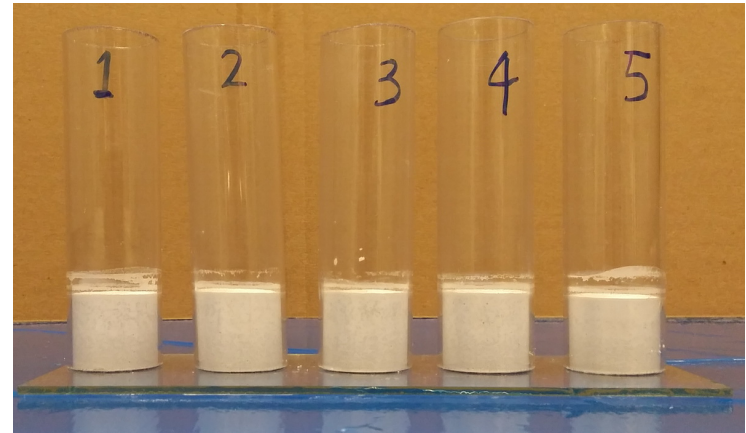

(b)

Figure 3: FGM mixing and solidification process.

\subsection{Mixing and curing Process}

Based on the mix design, the component materials were measured and placed in a sequence of HDPE, Al and ethanol, and then mixed in a Hobart mixer for about 6 minutes with an interrupt at every 2 minutes. Half 
of the measured ethanol was introduced into the mixture before mixing and two quarters of the rest ethanol were added in each interrupt. The mixed suspension was then dumped into an aluminum mold clamped on a shaker as shown in Figure 3 (a). Thereafter, the mold with the mixed suspension was vibrated for 30 seconds at a power amplitude of 80 . The vibration frequency of the shaker is $75 \mathrm{~Hz}$, and the horizontal and vertical vibration accelerations are 3 and 5 times of gravity, respectively. After the vibration was applied, the mixed suspension was kept in the mold allowing further sedimention of Al particles in the suspension. During this process, the ethanol will be completely drained off for about 24 hours. At the meanwhile, five transparent PVC tubes with four located in the corners and one at the center of the mold were embedded in the suspension to prepare small cylinder samples for later gradation analysis (see Figure 3 (b)), the quality of the gradation of the FGM can be also visualized through the transparent tubes.

\subsection{Gradation Analysis}

In order to evaluate the gradation quality of the mixed powder, the five cylinder samples prepared by the transparent tubes were taken out and separated into five uniform layers through their thicknesses. Based on those five composite samples, the volume fraction of $\mathrm{Al}$ particles and HDPE powders were measured and the gradation of the FGM were quantified. For this purpose, a modified Rice method was developed to measure the density of mixed powder. The test procedures of the modified Rice method are provided in Appendix A. Based on the test density of the mixed composites, the volume fraction of $\mathrm{Al}\left(\mu_{a}\right)$ and that of $\operatorname{HDTP}\left(\mu_{h}\right)$ in each layer can be determined by Eqs. (1) and (2):

$$
\begin{gathered}
\mu_{a}=\frac{\rho_{p}-\rho_{h}}{\rho_{a}-\rho_{h}} \\
\mu_{h}=\frac{\rho_{a}-\rho_{p}}{\rho_{a}-\rho_{h}}
\end{gathered}
$$

where $\rho_{a}, \rho_{h}$ and $\rho_{p}$ are the density of Al, HDTE and mixed powder, respectively, $\mu_{a}$ and $\mu_{h}$ are the volume fraction of the $\mathrm{Al}$ and HPDE, respectively.

The volume fraction of different layers of the mixed FGM along its thickness direction is shown in Table 1, where Layer 1 denotes the bottom layer with more sedimented aluminum powder, while Layer 5 represents the top layer with more suspension of HDPE. The sediments of the mixed powder from layer 1 to layer 5 are shown in Figure 4 (a). The gradually variation of the mixed components of the FGM along its thickness direction from the transparent container shown in Figure 4(a) also provides a clear visualization of the gradation quality of the casted FGM. The gradation analysis results in terms of the volume fraction of Al and HDPE shown in Figure 4 (b) shows a linear gradation of the components along its thickness direction.

Table 1: Volume fraction of the mixed powder

\begin{tabular}{|c|c|c|c|c|c|}
\hline & Layer 1 & Layer 2 & Layer 3 & Layer 4 & Layer 5 \\
\hline Volume $\left(\mathrm{mm}^{3}\right)$ & 5.56 & 5.50 & 5.51 & 5.60 & 5.33 \\
\hline Density $\left(\mathrm{g} / \mathrm{mm}^{3}\right)$ & 1.73 & 1.56 & 1.43 & 1.21 & 1.06 \\
\hline$\mu_{a}(\%)$ & 45.5 & 34.2 & 28.4 & 16.1 & 7.9 \\
\hline$\mu_{h}(\%)$ & 54.5 & 65.8 & 71.6 & 83.9 & 92.1 \\
\hline
\end{tabular}

\subsection{FGM panel solidification}

After the ethanol was completely drained off from the suspension, the graded Al-HDPE mixed composites with the aluminum mold were placed in a vacuum oven and heated up to a temperature of $170^{\circ} \mathrm{C}$ (begin to be melt at about $160^{\circ} \mathrm{C}$ at normal air pressure as shown in Figure 5 (a)). When the HDPE is fully melt, the vacuum valve was turned on and the air pressure inside the vacuum was gradually decreased to $500 \mu T$. 


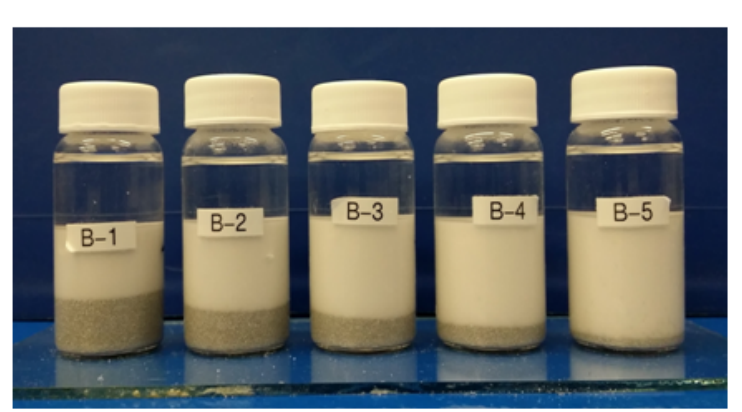

(a)

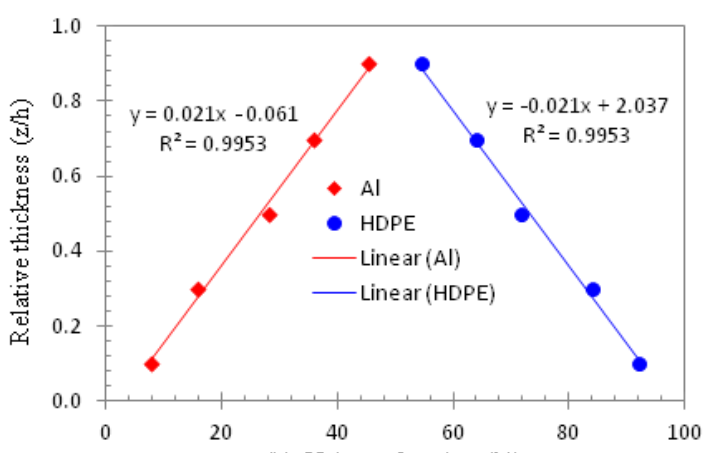

(b) Volume fraction (\%)

Figure 4: Sediment distribution of the mixed comoposites

This degassing process takes about 6 hours, which was designed to take away as much air voids as possible in the final FGM in order that the thermal conductivity of the FGM will be maximized. Nevertheless, it was observed that certain amount of air voids will always remain in the cured sample as shown in Figure 5 (b) even much longer vacuum was applied. The sample was cured in the vacuum oven at $170{ }^{\circ} \mathrm{C}$ with the vacuum valve turned on for about 1 hour, then the vacuum oven was turned off and an aluminum plate cover was applied with certain extra weight (about $100 \mathrm{lbs}$ in this study). After 2 more hours curing by heating up the sample back to $170{ }^{\circ} \mathrm{C}$, the whole set up was turned off and the FGM sample was removed from the mold when the temperature cools down to the room temperature.

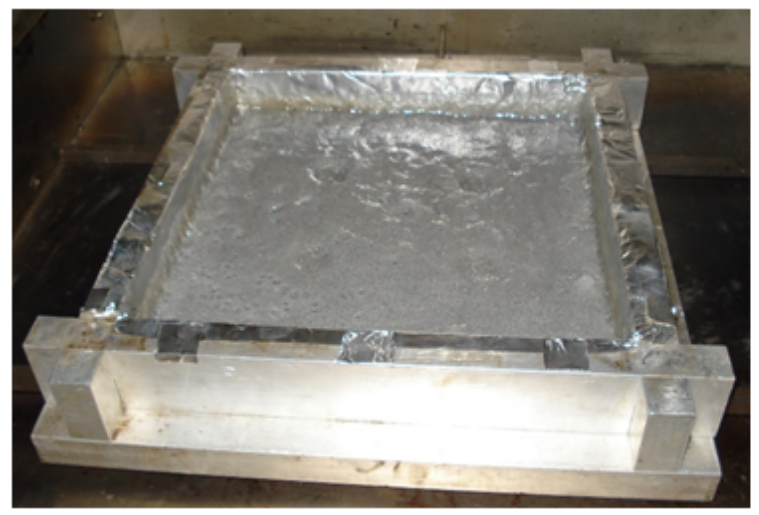

(a)

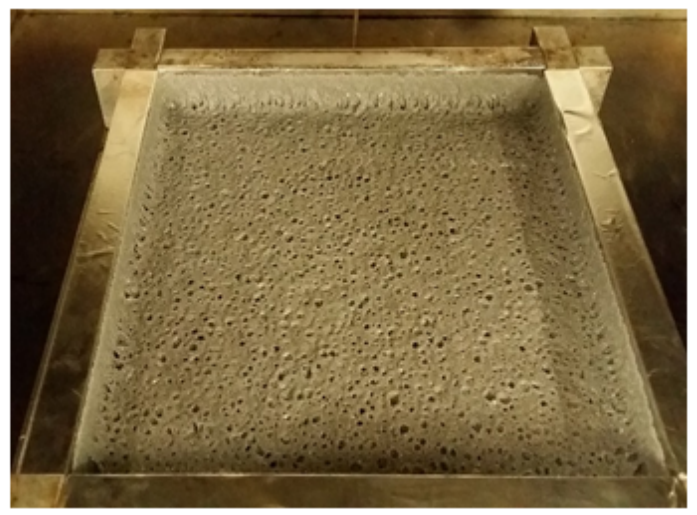

(b)

Figure 5: Fabrication of FGM panel: (a) melting of FGM in vacuum Owen; and (b) residual air voids in the vacummed FGM sample.

The cross section of one sample element $(0.5$ " height $\times 0.8$ " width) cut from the FGM panel is shown in Figure 6, which shows that a well controlled graded FGM was achieved by the proposed vibration and sedimentation combined approach.

\section{Mechanical properties characterizations}

In order to characterize the material properties of the FGM, a series of thermo-mechanical experimental tests were conducted. Six uniform Al-HDPE composite panels with 6 different volume fractions (10\%, $20 \%, 30 \%, 40 \%, 50 \%$, and $60 \%$ of Al to HDPE) were cast. From the thermo-mechanical properties of those six uniform composite samples, the material properties of the FGM will be interpolated based on the volume fraction of $\mathrm{Al}$ and HDPE in the FGM obtained by the gradation analysis conducted in subsection 


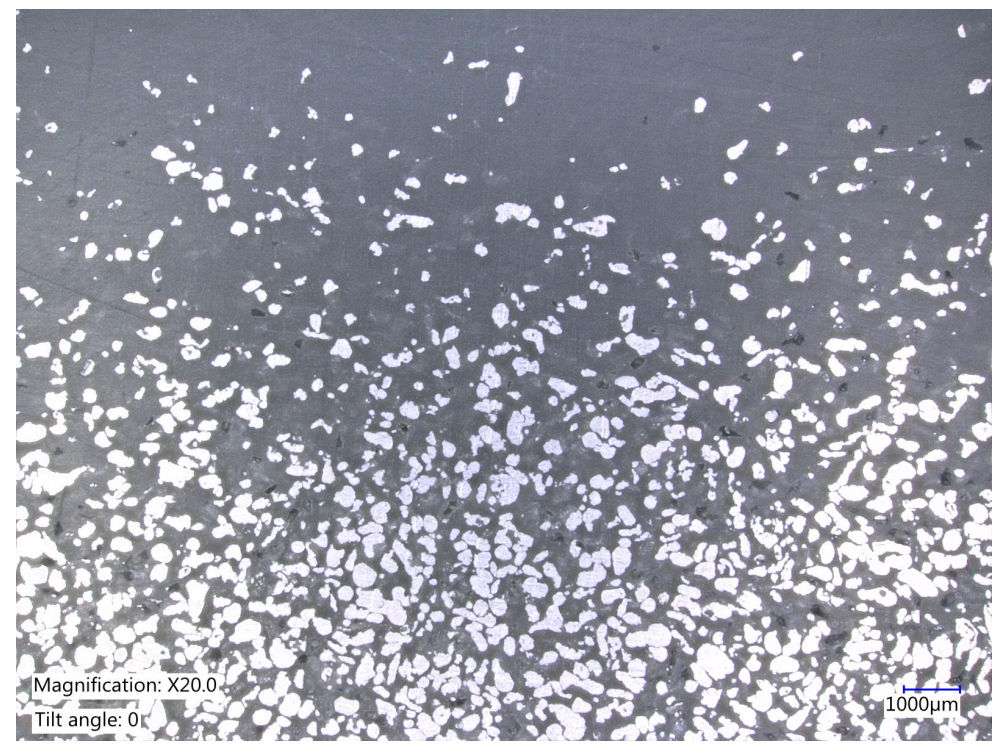

Figure 6: Gradation of the FGM panel

2.4. The sample preparation of those 6 composite panels followed the same mixing, curing and solidification procedures with those of the FGM panel except that the vibration process was not executed. Individual coupon specimens for mechanical and thermal property characterizations were sampled from those six uniform composite panels, which will described in detail in the following subsections. Typical microstructures of the composite samples were shown in Figure 7.

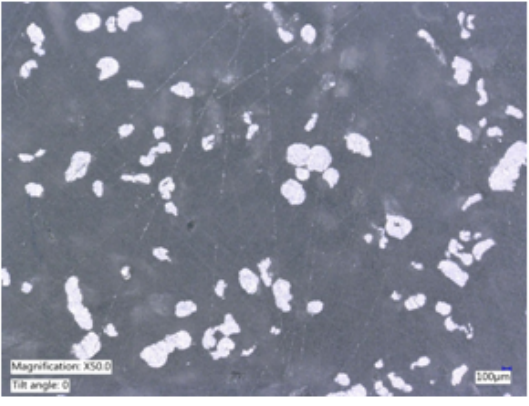

(a)

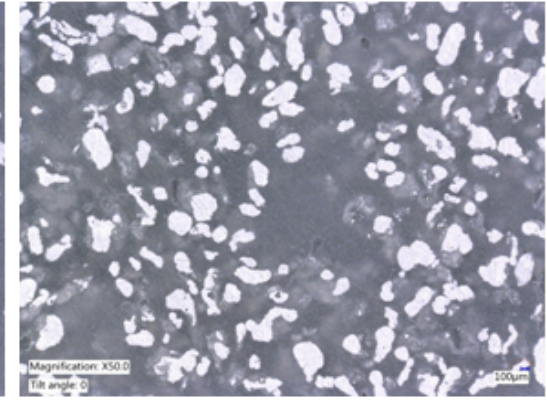

(b)

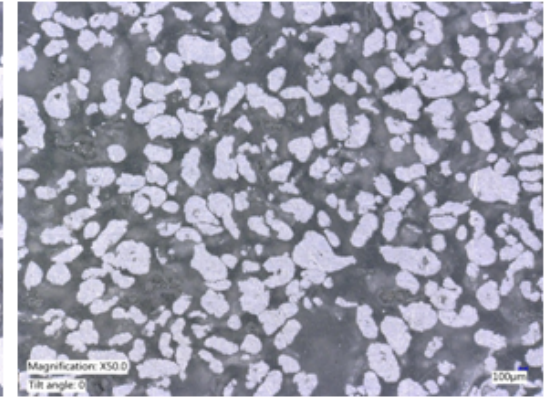

(c)

Figure 7: Microstructures of Al-HDPE composite with different volume fractions: (a) 10\%; (b) 30\%; and (c) $60 \%$.

From the six uniform Al-HDPE composite panels, six groups of coupon samples with dimensions of 9" (length) $\times 1$ " (width) $\times 0.5$ " (thickness) were prepared for tensile test with three replications for each group, which is shown in Figure 8(a). Two strain gages were bonded to each sample near the center, one is in alignment with while the other is perpendicular to the loading direction, respectively. ASTM D638(2010) [22] was followed to conduct the tensile test, from which the mechanical properties such as strength, modulus and Poisson's ratio of the composites with different volume fractions of Al were determined.

The Instrom 5984 34k Universal Testing Machine was used to apply a uniform tensile load on each sample. The load was applied at a strain rate of $0.02 \mathrm{inch} / \mathrm{min}$ until the samples were failed. A typical tensile loading curve is shown in Figure 8(b). It shows from Figure 8(b) that there is no obvious linear region along the entire loading curve for this polymer matrix composites. Thus the secant modulus was determined for each sample by following ASTM D638 (2010), where the zero-strain point was constructed 


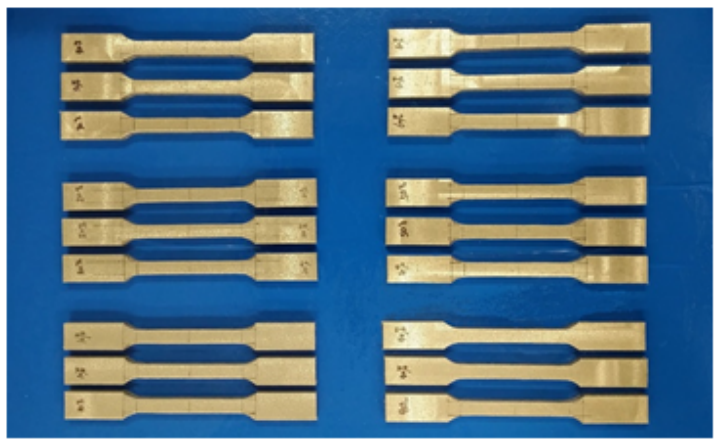

(a)

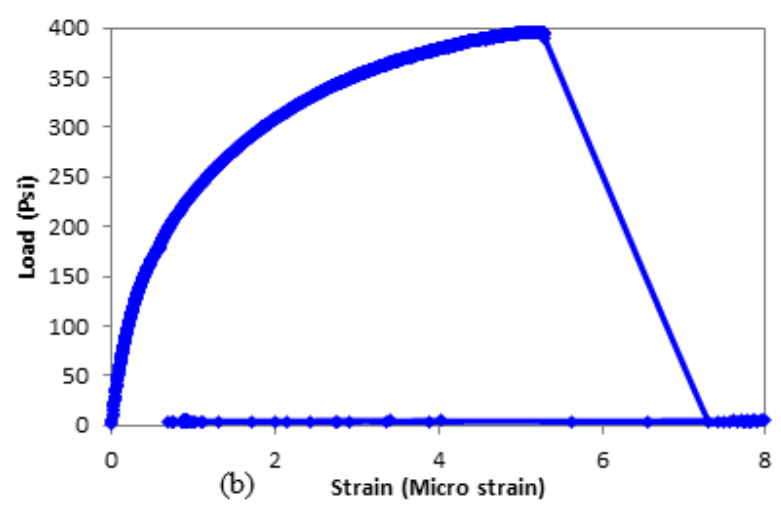

(b)

Figure 8: Tensile test: (a) Testing samples; and (b) Typical tensile loading curve..

at the inflection point through the toe correction method and the intersection point was chosen as the one corresponding to $40 \%$ of the peak stress. The strength of each sample was obtained by the peak load from the loading curve; and the Poisson's ratio was derived by curve-fitting of the negative lateral strain over the vertical strain. The test results are summarized in Table 2 . The air voids in the particulate composite samples with different volume fractions of Al particles were calculated by measuring the sample densities, which are also reported in Table 2. It clearly shows that much more air voids were accumulated in the composites when the volume fractions of $\mathrm{Al}$ particles get higher.

\section{Thermal physical properties characterizations}

The FGM proposed in this study is designed such that a high thermal conductivity will be achieved at the top part attaching to the solar cells while low thermal conductivity in the bottom to improve the working efficiency of the solar panel and reduces the cost of the panel as well. Therefore, it's essential to know the thermal properties such as thermal expansion coefficient and thermal conductivity of the designed FGM through its thickness direction.

\subsection{Thermal expansion coefficients}

To examine the thermal expansion coefficient (TEC) of the designed FGM through its thickness direction, six groups of samples with dimensions of 3/8" (diameter) $\times 1$ " (length) (Figure 9(a)) were prepared with four replications for each group. All samples were tested by the Orton Dilatometer (shown in Figure 9(a)) within a temperature range of $40^{\circ} \mathrm{C}$ to $120^{\circ} \mathrm{C}$.

A typical percent linear change (PLC) curve of a sample with respect to the scanning temperature is shown in Figure 10(a). As expected, the PLC gradually increases as the temperature increases. However, for the studied polymer matrix based composites, the PLC increasing shows a non-proportional pattern with respect to the scanned temperature. In order to obtain the TECs in an overall sense over this temperature range, the TECs of each sample were determined by linear regression of the PLC curve, i.e., equaling to the slope of the regressed line, which are summarized in Table 3. The variance of TEC of the composite sample with respect to the volume fraction of Al to HDPE is shown in Figure 10(b), indicating that the TEC approximately decreases as the volume fraction of $\mathrm{Al}$ increases.

\subsection{Thermal conductivity}

To examine the thermal conductivity of the designed FGM through its thickness direction, six groups of samples with dimensions of 0.5 " (length) $\times 0.5$ " (width) $\times 0.5$ " (thickness) (Figure 11(a)) were prepared with five replications for each group. The thermal diffusivity of each composite sample was measured by 
Table 2: Tensile test results of Al-HDPE composite with different volume fractions of Al and HDPE.

\begin{tabular}{|c|c|c|c|c|c|c|c|c|c|}
\hline & \multicolumn{9}{|c|}{ Volume Fraction } \\
\hline Mixing & \multicolumn{3}{|c|}{$10 \%$} & \multicolumn{3}{|c|}{$20 \%$} & \multicolumn{3}{|c|}{$30 \%$} \\
\hline & Strength & Modulus & $v$ & Strength & Modulus & $v$ & Strength & Modulus & $v$ \\
\hline Sample & $(\mathrm{MPa})$ & (GPa) & & (MPa) & $(\mathrm{GPa})$ & & $(\mathrm{MPa})$ & (GPa) & \\
\hline 1 & 15.771 & 1.371 & 0.378 & 14.731 & 1.542 & 0.333 & 12.091 & 2.205 & 0.293 \\
\hline 2 & 15.868 & 1.257 & 0.446 & 14.667 & 1.665 & 0.308 & 11.358 & 2.431 & 0.296 \\
\hline 3 & 17.633 & 1.307 & 0.365 & 14.573 & 1.678 & 0.366 & 11.726 & 2.001 & 0.307 \\
\hline Ave & 16.424 & 1.312 & 0.396 & 14.657 & 1.628 & 0.336 & 11.725 & 2.212 & 0.299 \\
\hline - & 0.653 & 0.055 & 0.031 & 0.084 & 0.086 & 0.028 & 0.367 & 0.211 & 0.006 \\
\hline+ & 1.209 & 0.059 & 0.050 & 0.074 & 0.050 & 0.030 & 0.366 & 0.219 & 0.008 \\
\hline Air void (\%) & \multicolumn{3}{|c|}{1.07} & \multicolumn{3}{|c|}{1.12} & \multicolumn{3}{|c|}{1.44} \\
\hline Mixing & \multicolumn{3}{|c|}{$40 \%$} & \multicolumn{3}{|c|}{$50 \%$} & \multicolumn{3}{|c|}{$60 \%$} \\
\hline & Strength & Modulus & $v$ & Strength & Modulus & $v$ & Strength & Modulus & $v$ \\
\hline Sample & $(\mathrm{MPa})$ & $(\mathrm{GPa})$ & & $(\mathrm{MPa})$ & $(\mathrm{GPa})$ & & (MPa) & $(\mathrm{GPa})$ & \\
\hline 1 & 10.266 & 2.633 & 0.277 & 9.513 & 2.683 & 0.254 & 8.357 & 2.539 & 0.207 \\
\hline 2 & 10.445 & 2.568 & 0.242 & 9.388 & 2.758 & 0.254 & 8.618 & 2.842 & 0.242 \\
\hline 3 & 10.832 & 2.840 & 0.278 & 9.548 & 2.779 & 0.236 & 8.447 & 2.735 & 0.222 \\
\hline Ave & 10.514 & 2.680 & 0.265 & 9.483 & 2.740 & 0.248 & 8.474 & 2.705 & 0.224 \\
\hline- & 0.248 & 0.112 & 0.024 & 0.095 & 0.057 & 0.012 & 0.117 & 0.166 & 0.017 \\
\hline+ & 0.318 & 0.160 & 0.012 & 0.065 & 0.039 & 0.006 & 0.144 & 0.137 & 0.019 \\
\hline Air void (\%) & \multicolumn{3}{|c|}{2.18} & \multicolumn{3}{|c|}{5.10} & \multicolumn{3}{|c|}{8.48} \\
\hline
\end{tabular}

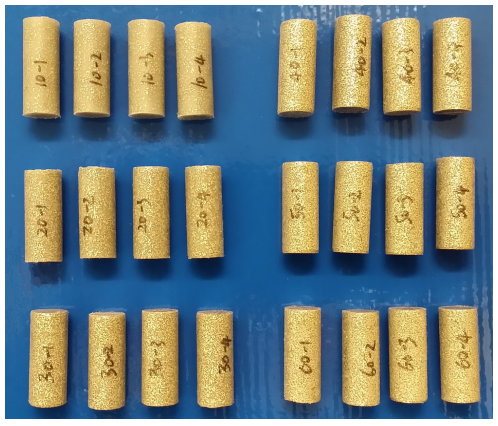

(a)

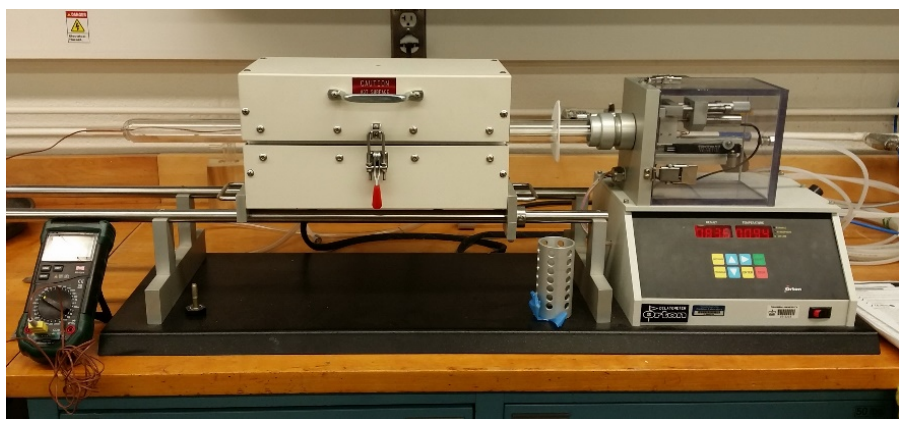

(b)

Figure 9: Measurement of thermal expansion coefficient: (a) prepared samples with different volume fraction of Al to HDPE; and (b) the Orton Dilatometer.

the LFA 447 NanoFlash Light Flash System, which allows for 4 samples being tested at the same time thus provides a quick, easy and cost-effective way to test the thermophysical properties of the composite materials. As the HDPE matrix has a relatively low emissivity or absorptivity, all the composite were coated with a thin layer of graphite film before testing. The graphite increases the energy absorbed on the flashed side and increases the temperature signal on the back side of the sample. To avoid any shine-through on lower filled samples, more layers of graphite coating were applied on the samples with lower volume fraction of Al particles. The test was conducted at room temperature by following the ASTM D5930 -09 [23]. A typical temperature rise signal with respect to the flashing time is shown in (Figure 11(b)).

The measured thermal diffusivity for each sample are summarized in Table 4. Once the thermal diffu- 


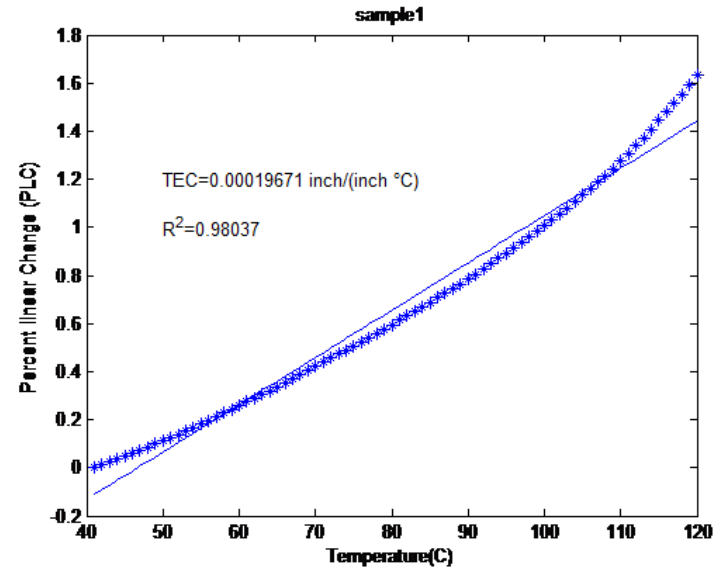

(a)

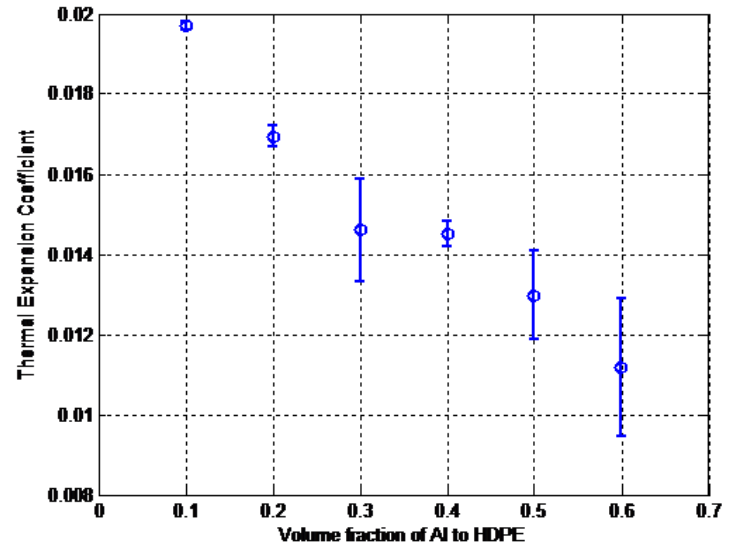

(b)

Figure 10: Thermal expansion coefficient: (a)Percent linear change (PLC) of the sample with respect to the temperature; and (b) Thermal expansion coefficients with respect to the volume fraction of Al to HDPE.

Table 3: Thermal expansion coefficient of Al-HDPE composite with different volume fractions of Al and HDPE.

\begin{tabular}{|c|c|c|c|c|c|c|}
\hline & \multicolumn{7}{|c|}{ Volume Fraction } \\
\hline sample & $10 \%$ & $20 \%$ & $30 \%$ & $40 \%$ & $50 \%$ & $60 \%$ \\
\hline 1 & 196.710 & 170.510 & 165.120 & 143.720 & 114.340 & 124.090 \\
\hline 2 & 195.960 & 165.580 & 137.960 & 149.990 & 130.470 & 123.390 \\
\hline 3 & 196.600 & 170.620 & 141.070 & 143.340 & 140.170 & 112.470 \\
\hline 4 & 198.620 & 171.100 & 139.880 & 143.740 & 134.050 & 87.320 \\
\hline Ave & 196.973 & 169.453 & 146.005 & 145.198 & 129.758 & 111.818 \\
\hline- & 1.012 & 3.873 & 8.055 & 1.858 & 15.418 & 24.498 \\
\hline+ & 1.648 & 1.647 & 19.115 & 4.792 & 10.413 & 12.273 \\
\hline
\end{tabular}

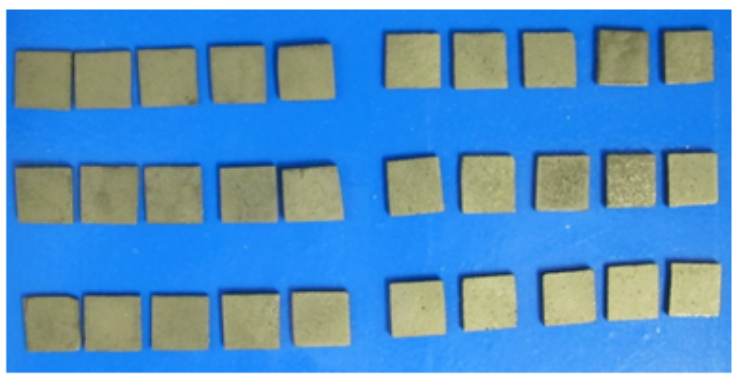

(a)

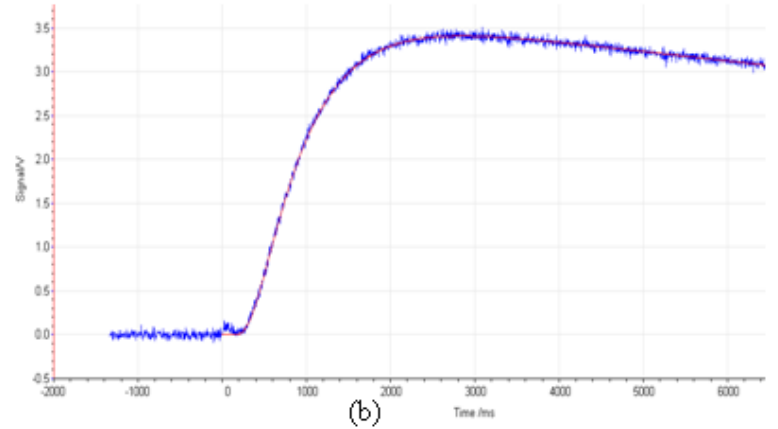

(b)

Figure 11: Measurement of thermal conductivity: (a) Prepared samples with differnt volume fractions of Al to HDPE; and (b) prepared samples with different volume fraction of Al to HDPE.

sivity is obtained, the thermal conductivity can be determined by the following formula:

$$
\lambda(T)=\alpha(T) * \rho(T) * c_{p}(T)
$$

where $\lambda, \alpha, \rho$ and $c_{p}$ are the thermal conductivity, diffusivity, the bulk density and specific heat capacity, respectively. 
Table 4: Thermal conductivity of Al-HDPE composite with different volume fractions of Al and HDPE.

\begin{tabular}{|c|c|c|c|c|c|c|c|c|c|c|c|c|}
\hline & \multicolumn{10}{|c|}{ Volume Fraction } \\
\hline & \multicolumn{2}{|c|}{$10 \%$} & \multicolumn{2}{c|}{$20 \%$} & \multicolumn{2}{c|}{$30 \%$} & \multicolumn{2}{c|}{$40 \%$} & \multicolumn{2}{c|}{$50 \%$} & \multicolumn{2}{c|}{$60 \%$} \\
\hline sample & $\alpha$ & $\lambda$ & $\alpha$ & $\lambda$ & $\alpha$ & $\lambda$ & $\alpha$ & $\lambda$ & $\alpha$ & $\lambda$ & $\alpha$ & $\lambda$ \\
\hline 1 & 0.514 & 1.082 & 0.721 & 1.532 & 1.007 & 2.134 & 1.279 & 2.787 & 1.632 & 3.444 & 2.192 & 4.458 \\
\hline 2 & 0.506 & 1.063 & 0.703 & 1.493 & 1.061 & 2.247 & 1.339 & 2.917 & 1.557 & 3.286 & 2.017 & 4.102 \\
\hline 3 & 0.517 & 1.088 & 0.683 & 1.451 & 1.081 & 2.290 & 1.304 & 2.841 & 1.507 & 3.181 & 2.132 & 4.336 \\
\hline 4 & 0.469 & 0.985 & 0.729 & 1.548 & 1.098 & 2.327 & 1.761 & 3.019 & 2.069 & 3.716 & 1.386 & 4.207 \\
\hline 5 & 0.519 & 1.092 & 0.816 & 1.733 & 1.064 & 2.254 & 1.366 & 2.976 & 1.810 & 3.820 & 2.064 & 4.198 \\
\hline Ave. & 0.505 & 1.062 & 0.730 & 1.551 & 1.062 & 2.250 & 1.335 & 2.908 & 1.653 & 3.490 & 2.095 & 4.260 \\
\hline- & 0.036 & 0.077 & 0.047 & 0.100 & 0.055 & 0.117 & 0.056 & 0.122 & 0.146 & 0.309 & 0.078 & 0.158 \\
\hline+ & 0.014 & 0.030 & 0.086 & 0.182 & 0.036 & 0.077 & 0.051 & 0.112 & 0.157 & 0.330 & 0.097 & 0.198 \\
\hline
\end{tabular}

The determined conductivity for all samples are also provided in Table 4, and the variance of the diffusivity and conductivity of the FGM samples with different volume fractions of Al to HDPE are shown in Figure 11(a) and (b), respectively.
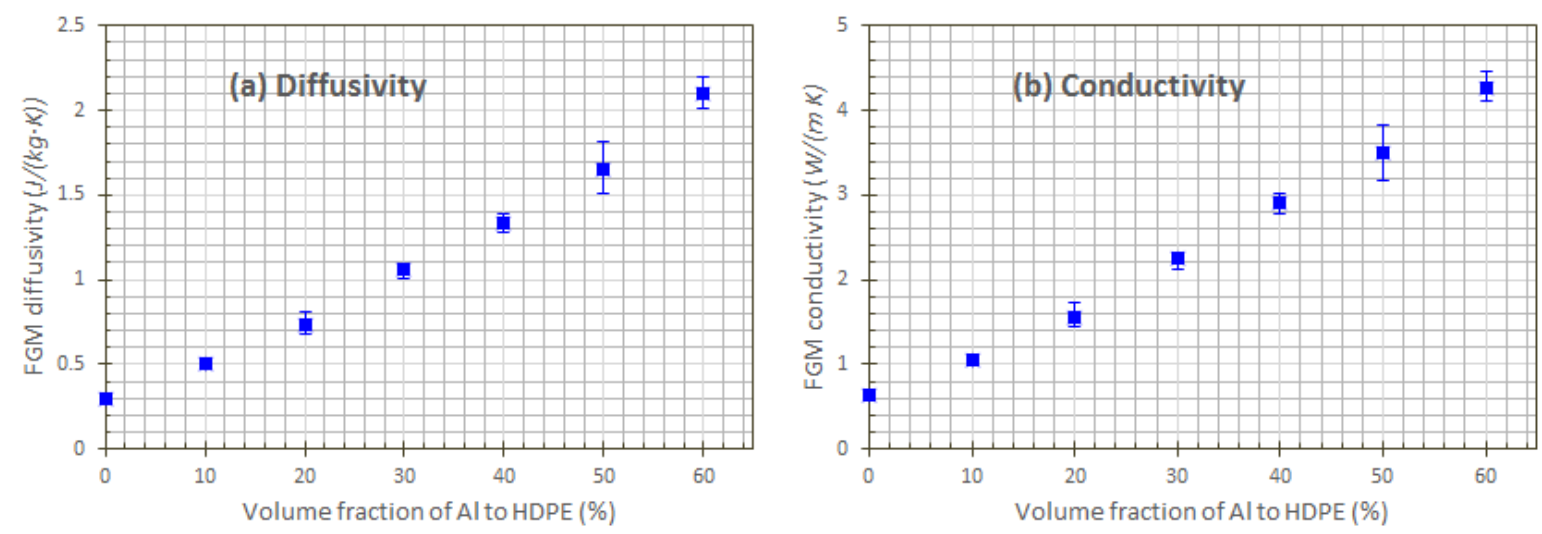

Figure 12: Thermal conductivity results with differnt volume fractions of Al to HDPE: (a) Thermal diffusivity; and (b) thermal conductivity.

\section{Evaluation of the thermal efficiency of the integrated FGM panel}

A $2 \mathrm{ft} \times 2 \mathrm{ft}$ prototype FGMs with water tubes (Figure 12) embedded was fabricated by the vibration and sedimentation combined approach in order to assess the thermal efficiency toward the green energy building envelope applications. The purpose of the designed double serpentine shape of the water tubes as shown in Figure 12(b) is to take away the heat within the panel more uniformly and thus keeps the temperatures of the panel surface much more uniform.

Thermal efficiency of the FGM panel with embedded water tubes was assessed at the Carleton Laboratory via the solar simulator assembled in a purpose-built room with a temperature-controlled exhaust system, which cools the room by forced-air ventilation as shown in Figure 13(a). For the Radiation Source, a special metal halide (MHG) lamp is used to (1) produce a dense multiline spectrum of the rare earths that is comparable to a continuous spectrum and (2) provide a spectral distribution very close to natural sunlight (Total Radiation as defined by CIE 85). The Solar Constant lamp is mounted to modular tracks located on the ceiling of the chamber. The lamp can be moved and rotated to suit specific testing needs. 


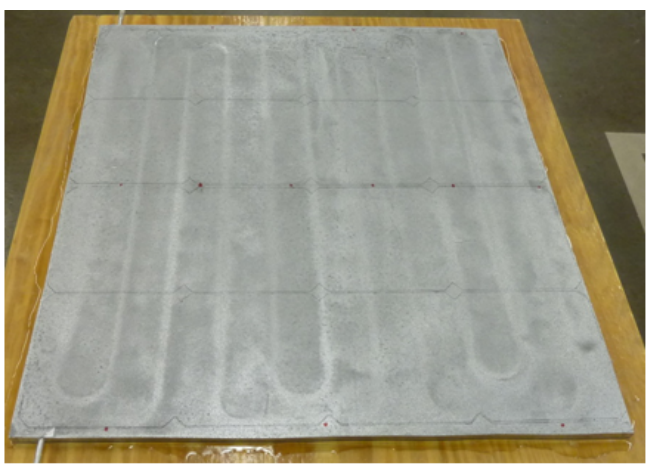

(a)

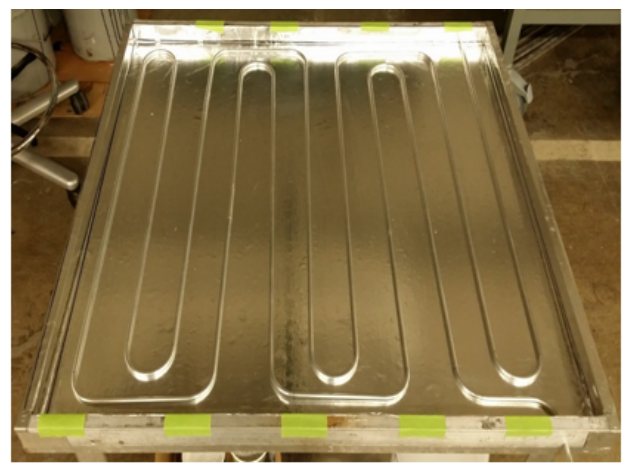

(b)

Figure 13: Integrated FGM panel: (a) FGM panel with water tube embedded; and (b) water flowing pattern.

A flow-meter (Figure 13(b)) was used to control the water flowing rate inside the water tube to cool down the surface temperature of the FGM panel as well as the solar cell. Fourteen thermal couples were applied to examine the temperature distribution throughout the whole panel surface, onto which solar cells will be mounted. Among those fourteen thermal couples, twelve (6 located at the two edges of the panel and other 6 were distributed at the center line on the solar panel) attached on the FGM panel; while two were attached on the inlet (No. 1) and outlet (No. 15) aluminum water tubes. The detailed distributions of the thermalcouples were shown in Figure 13(c). The temperature readings from the thermal-couples were acquired by a developed data acquisition system shown in Figure 13(a) with a sampling frequency of $2 \mathrm{~Hz}$.

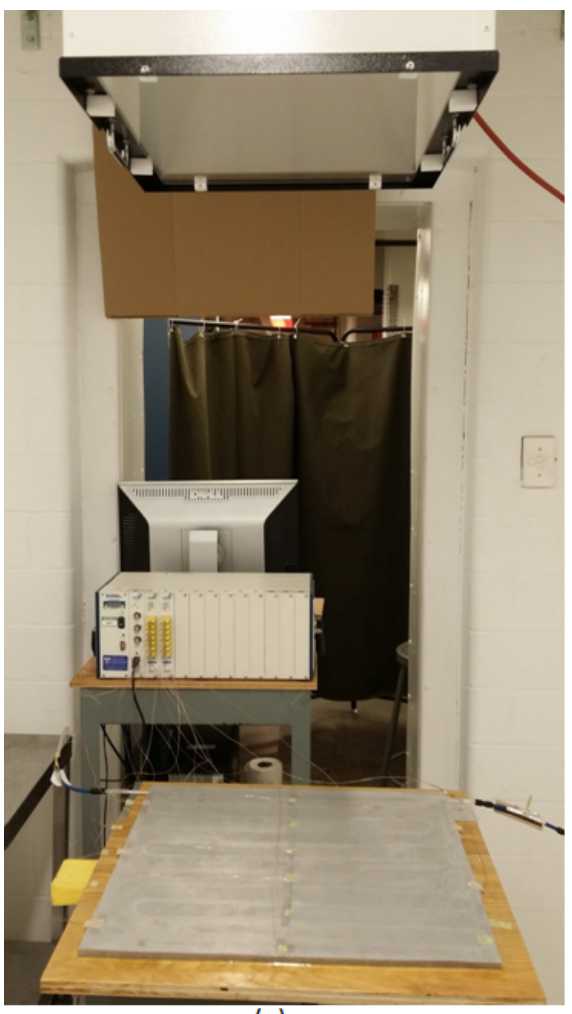

(a)
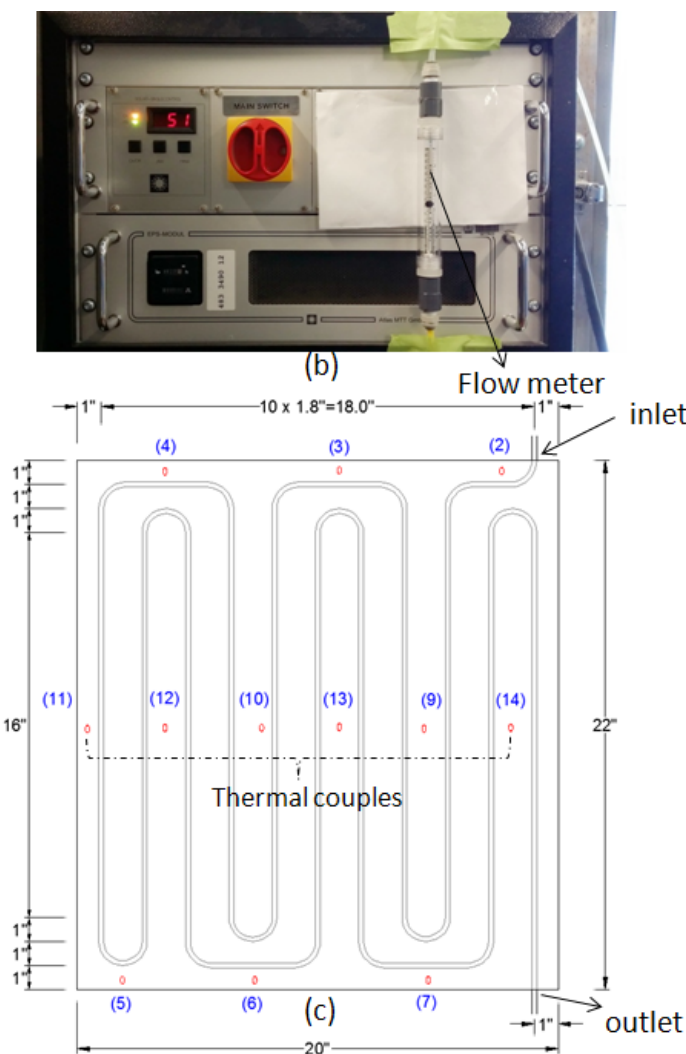

Figure 14: Thermal performance assessment of the integrated FGM panel: (a) Solar room testing configuration; (b) solar intensity controller; and (c) illustration of thermalcouple locations. 
The test consists of two stages. In the first stage, the FGM panel was exposed to the solar radiation without water flowing inside until a stable state was reached; while in the second stage, a stable water flow was introduced and controlled by the flow meter until another stable state was reached. A preliminary test result of the FGM panel under an irradiation level of $620 \mathrm{w} / \mathrm{m}^{2}$ is presented in (Figure 15). It shows that the temperature of the panel gradually increases in the first stage as continuous irradiation energy absorbed and accumulated in the panel. Under the selected irradiation level $\left(620 \mathrm{w} / \mathrm{m}^{2}\right)$, it takes about 2.5 hours for the FGM panel reaching to a stable peak temperature. As expected, the peak temperatures at the two edges are lower than those at the central line of the panel. Figures 14 shows that the average peak temperatures at two edges and in the central line get to $47.5^{\circ} \mathrm{C}$ and $52^{\circ} \mathrm{C}$, respectively under the selected irradiation level. Since the water circuit was closed in the first stage, the temperature of both the inlet and outlet water initially increased and then reached to a stable state in a much shorter period compared with those on the FGM panel surface.

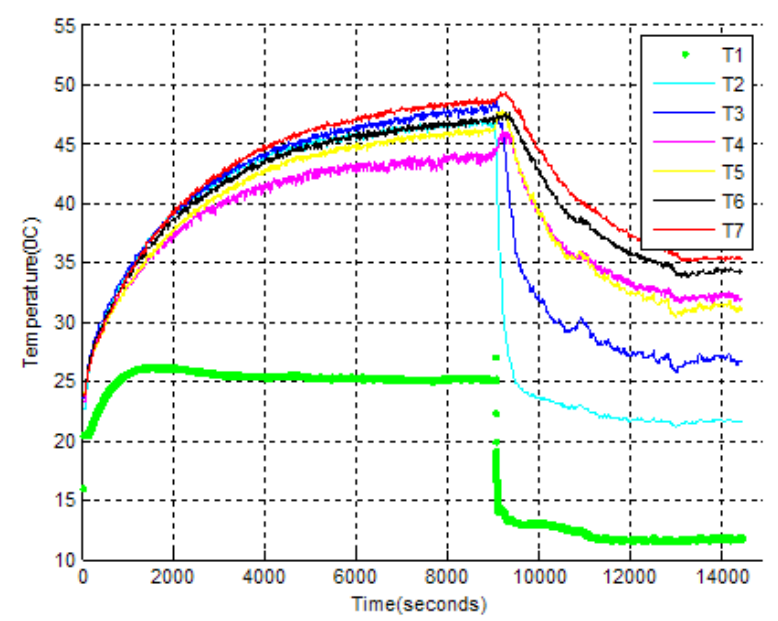

(a)

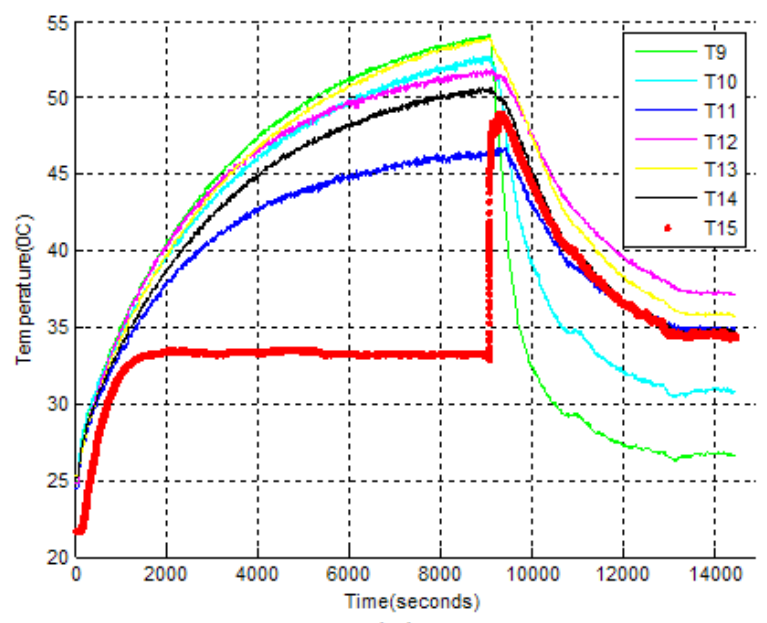

(b)

Figure 15: Temperature evolution of the integrated FGM panel under solar irradiation: (a) Inlet and edge of the FGM panel; and (b) outlet and center line of the FGM panel.

When the temperature of the panel reach to a peak stable one, the water valve was turned on and a stable water flowing was introduced and controlled by the flow meter. In this preliminary test, a relatively small flowing rate $(60 \mathrm{ml} / \mathrm{min})$ was studied. Figure 15 shows that, in this second stage, the FGM panel surface temperatures rapidly drop as the water flowing through the tubes embedded in the panel. Under this small flowing rate, it takes about 1 hour for the panel to cool down to another stable state. Similar to the first stage, the temperate at the edge parts is lower than that in the central line of the panel because of the closer and more direct of solar irradiations in the central line than that at the edges. It shows from Figure 15 that the temperature drops approximately range from $15^{\circ} \mathrm{C}$ to $25^{\circ} \mathrm{C}$ with an average drop of $18.7^{\circ} \mathrm{C}$. Once the water flow was introduced, the temperature on the inlet water tube suddenly drops as cool water source flows into the circuit; while on the other hand, the temperature on the outlet water tube suddenly increases as heated water fluxes out from the outlet water tube. Thereafter, the outlet water temperature gradually decreases as the water continues flowing in the circuit until it reaches to the second stable state which is about $34.5^{\circ} \mathrm{C}$. The temperature of the water source used in this study is $12.2^{\circ} \mathrm{C}$. Therefore, this performance assessment test showed a $22.3^{\circ} \mathrm{C}$ water temperature increase and an average $18.7^{\circ} \mathrm{C}$ surface temperature decrease of the FGM panel, which indicates that significant PV conversation efficiency improvement can be achieved for both electricity generation and heat collection by the presented FGM roofing panel toward green energy building envelope applications. 


\section{Summary and Conclusion}

In this study, an Aluminum/High-Density Polyethylene functionally graded material has been fabricated as an essential component of a multifunctional building envelope with high performance for energy efficiency and sustainability. The mass production of the FGM was realized by using coarse aluminum particles and fine HDPE powders through a vibration and sedimentation combined approach. The gradation of the FGM across its thickness direction was analyzed by developing a modified Rice method. In order to characterize the material properties of the FGM, a series of thermo-mechanical experimental tests were conducted by casting uniform Al-HDPE composite panels with 6 different volume fractions (10\%, 20\%, $30 \%, 40 \%, 50 \%$, and $60 \%$ of Al to HDPE). The material properties of the FGM such as modulus, Poisson ratio, thermal expansion coefficients and thermal conductivities were obtained by a series of laboratory tests. From the thermo-mechanical properties of those six uniform composite samples, the material properties of the FGM can be interpolated based on the volume fraction of Al and HDPE in the FGM obtained by the gradation analysis. It was observed that more air voids exhibited in the solidified composites when the volume fraction of $\mathrm{Al}$ particles get higher. Because of the existence of the air voids, the modulus of the particulate composite will not increase or even decrease as the volume fraction of $\mathrm{Al}$ particles reach to a certain threshold value.

A $2 \mathrm{ft} \times 2 \mathrm{ft}$ prototype FGMs with water tubes embedded was further fabricated by the vibration and sedimentation combined approach in order to assess the thermal efficiency. Under an irradiation level of 620 $\mathrm{w} / \mathrm{m}^{2}$ and a flowing rate of $60 \mathrm{ml} / \mathrm{min}$, the performance assessment test showed a $22.3^{\circ} \mathrm{C}$ water temperature increase and an average $18.7^{\circ} \mathrm{C}$ surface temperature decrease of the FGM panel, which demonstrates that significant PV conversation efficiency improvement can be achieved for both electricity generation and heat collection by the presented FGM roofing panel toward green energy building envelope applications.

From the performance assessment conducted in this study, it is anticipated that under the same solar irradiation intensity, the higher the water flow rate is introduced, the more surface temperature decrease will be obtained and consequently a higher electricity generation efficiency will be achieved; while on the other hand more water will be required but lower water temperature increase will be generated for domestic applications. In this sense, in order to reach an optimum balance among more energy output, higher temperature water for domestic applications, and lower water resource consumption, more experimental evaluation and calibrations are required for the final BIPVT product, which will be our further research emphasis in the near future.

\section{Acknowledgement}

This work is sponsored by the National Science Foundation CMMI 0954717, CMMI 1301288, and CMMI 1301160, whose support is gratefully acknowledged. The authors appreciate Dr. Pohua Li, Dr. Mingzhen Chen, Dr. Liming Li, Mr. Joao Silva and Mr. Rodolfo Kusma for their contributions on the laboratory testing. The authors also appreciate the support of the Henry Mitchell Weitzner Research Fund, which has been and will be used in his research of roofing materials for solar energy applications and technologies.

\section{Appendix}

Test procedures of the modified Rice method:

1) Measure the net weight of a clean and dry bottle $M_{b}$;

2) Introduce ethanol with a known density $\rho_{e}$ into the bottle until full, write down the volume of the introduced ethanol $V_{e 1}$;

3) Measure the total weight of the bottle and the introduced ethanol $M_{T 1}=M_{b}+M_{e 0}$; 
4) Calculate the volume of the introduced ethanol $V_{e 2}=M_{e 0} / \rho_{e}$; if the difference between $V_{e 1}$ and $V_{e 2}$ is larger than $1 \%$, repeat step 2 . The final volume of the bottle is determined by $V_{b}=\left(V_{e 1}+V_{e 2}\right) / 2$;

5) Introduce the mixed dry powder into the bottle, measure the total weight of bottle and dry powder $M_{T 2}$;

6) Calculate the weight of the mixed dry powder $M_{p}=M_{T 2}-M_{b}$;

7) Fill certain amount of ethanol into the bottle and make a uniform suspension by carful shaking to avoid any liquid splash out;

8) Place the bottle with suspension into a vacuum to get rid of the air void in the suspension, gradually decrease the air pressure to a vacuum stage of 45 Torr at room temperature for 30 minutes;

9) Take out the bottle from the vacuum and refill it until full, measure the total weight of the bottle, powder and ethanol $M_{T 3}$;

10) Calculate the net weight of ethanol in the bottle $M_{e}=M_{T 3}-M_{T 2}$;

11) Calculate the volume of ethanol in the bottle $V_{e}=M_{e} / \rho_{e}$;

12) Calculate the volume of the mixed powder $V_{p}=V_{b}-V_{e}$;

13) Calculate the density of the mixed powder $\rho_{p}=M_{p} / V_{p}$.

\section{References}

[1] 2011 Buildings Energy Data Book, U.S. Department of Energy: Energy efficiency and renewable energy (2011).

[2] B. P. Jelle, C. Breivik, State-of-the-art Building Integrated Photovoltaics, Energy Procedia 20 (2012) 68-77. doi:10.1016/j.egypro.2012.03.009.

[3] F. L. Chen, D. J. Yang, H. M. Yin, Application, in: Semiconductor Materials for Solar Photovoltaic Cells, Vol. 218 of Springer Series in Materials Science, Springer International Publishing, 2015.

[4] B. Petter Jelle, C. Breivik, H. Drolsum Rkenes, Building integrated photovoltaic products: A state-ofthe-art review and future research opportunities, Solar Energy Materials and Solar Cells 100 (2012) 69-96. doi:10.1016/j.solmat.2011.12.016.

[5] C. D. Corbin, Z. J. Zhai, Experimental and numerical investigation on thermal and electrical performance of a building integrated photovoltaicthermal collector system, Energy and Buildings 42 (1) (2010) 76-82. doi:10.1016/j.enbuild.2009.07.013.

[6] C. Peng, Y. Huang, Z. Wu, Building-integrated photovoltaics (BIPV) in architectural design in China, Energy and Buildings 43 (12) (2011) 3592-3598. doi:10.1016/j.enbuild.2011.09.032.

[7] M. Sabry, Y. A. Abdel-Hadi, A. Ghitas, PV-integrated CPC for transparent faades, Energy and Buildings 66 (2013) 480-484. doi:10.1016/j.enbuild.2013.07.059.

[8] J. Hu, W. Chen, B. Zhao, H. Song, Experimental studies on summer performance and feasibility of a BIPV/T ethylene tetrafluoroethylene (ETFE) cushion structure system, Energy and Buildings 69 (2014) 394-406. doi:10.1016/j.enbuild.2013.10.033.

[9] N. W. Alnaser, Building integrated renewable energy to achieve zero emission in Bahrain, Energy and Buildings 93 (2015) 32-39. doi:10.1016/j.enbuild.2015.01.022.

[10] H. Fathabadi, Increasing energy efficiency of PV-converter-battery section of standalone building integrated photovoltaic systems, Energy and Buildings 101 (2015) 1-11. doi:10.1016/j.enbuild.2015.04.024. 
[11] D. Yang, H. Yin, Energy Conversion Efficiency of a Novel Hybrid Solar System for Photovoltaic, Thermoelectric, and Heat Utilization, IEEE Transactions on Energy Conversion 26 (2) (2011) 662670. doi:10.1109/TEC.2011.2112363.

[12] H. M. Yin, D. J. Yang, G. Kelly, J. Garant, Design and performance of a novel building integrated PV/thermal system for energy efficiency of buildings, Solar Energy 87 (2013) 184-195. doi:10.1016/j.solener.2012.10.022.

[13] E. Skoplaki, J. Palyvos, On the temperature dependence of photovoltaic module electrical performance: A review of efficiency/power correlations, Solar Energy 83 (5) (2009) 614-624. doi:10.1016/j.solener.2008.10.008.

[14] J. J. Lannutti, Functionally graded materials: Properties, potential and design guidelines, Composites Engineering 4 (1) (1994) 81-94. doi:10.1016/0961-9526(94)90010-8.

[15] I. H. Tavman, Thermal and mechanical properties of aluminum powder-filled high-density polyethylene composites, Journal of Applied Polymer Science 62 (12) (1996) 2161-2167. doi:10.1002/(SICI)1097-4628(19961219)62:12;2161::AID-APP19;3.0.CO;2-8.

[16] P. R. Marur, H. V. Tippur, Evaluation of mechanical properties of functionally graded materials, Journal of Testing and Evaluation (1998) 539-545.

[17] Y. Zhong, M.-J. Pindera, S. M. Arnold, Efficient Reformulation of HOTFGM: Heat Conduction with Variable Thermal Conductivity, Tech. rep. (Nov. 2002).

[18] Y. J. Liu, H. M. Yin, Equivalent inclusion method-based simulation of particle sedimentation toward functionally graded material manufacturing, Acta Mechanica 225 (4-5) (2014) 1429-1445. doi:10.1007/s00707-013-1058-0.

[19] P. Lee, H. Yin, Size effect on functionally graded material fabrication by sedimentation, Journal of Nanomechanics and Micromechanics 5 (2) (2015) A4014008. doi:10.1061/(ASCE)NM.21535477.0000087.

[20] L. Yang, H. Yin, Parametric study of particle sedimentation by dissipative particle dynamics simulation, Physical Review E 90 (3) (2014) 033311, wOS:000342146000008. doi:10.1103/PhysRevE.90.033311.

[21] D. J. Yang, Z. F. Yuan, P. H. Lee, H. M. Yin, Simulation and experimental validation of heat transfer in a novel hybrid solar panel, International Journal of Heat and Mass Transfer 55 (4) (2012) 1076-1082. doi:10.1016/j.ijheatmasstransfer.2011.10.003.

[22] ASTM D638 - 10, Test method for tensile properties of plastics, Tech. rep., ASTM International (2010).

[23] ASTM D5930- 09, Standard test method for thermal conductivity of plastics by means of a transient line-source technique, Tech. rep., ASTM International (2009). 